\title{
Bismuth intoxication resulting in acute kidney injury in a pregnant adolescent girl
}

\author{
Aslı Çelebi-Tayfur ${ }^{1}$, Raziye Merve Yaradılmış², Fatma Ulus ${ }^{3}$, Aysun Çaltık-Yılmaz', \\ Esra Özayar ${ }^{3}$, Berrin Koşar ${ }^{3}$, Bahar Büyükkaragöz ${ }^{1}$, Eyüp Horasanlı ${ }^{3}$ \\ Departments of ${ }^{2}$ Pediatrics, ${ }^{1}$ Pediatric Nephrology and ${ }^{3}$ Anesthesiology and Reanimation, Keçiören Training and Research \\ Hospital, University of Health Sciences, Ankara, Turkey. E-mail: as_celebi@hotmail.com \\ Received: 18th December 2017, Revised: 11th February 2018, 8th April 2018, Accepted: 14th May 2018
}

SUMMARY: Çelebi-Tayfur A, Yaradılmış RM, Ulus F, Çaltık-Yılmaz A, Özayar E, Koşar B, Büyükkaragöz B, Horasanlı E. Bismuth intoxication resulting in acute kidney injury in a pregnant adolescent girl. Turk J Pediatr 2019; 61: 292-296.

Bismuth intoxication is a rare cause of acute kidney injury (AKI) and is usually reversible by appropriate therapeutic measures. We present here a case of an adolescent pregnant girl who developed AKI due to an overdose of colloidal bismuth subcitrate (CBS, total amount of $6 \mathrm{~g}$ ). She received parenteral chelating agent dimercaprol for 14 days. Continuous venovenous hemodiafiltration (CVVHD) with high-flux membrane was carried out in the first 3 days of chelating therapy and intermittent hemodialysis for 11 days, thereafter. The patient recovered clinically and was discharged after 21 days. She gave birth to a healthy term boy. At the last visit, the baby was 6 months old with normal growth and development as well as normal kidney functions. Neither deterioration in renal functions nor emergence of proteinuria was recorded in the patient during follow-up care after hospital discharge. In cases of AKI due to an overdose of CBS, treatment with dimercaprol combined with high flux hemodiafiltration and subsequently hemodialysis appears to be both useful and safe for bismuth elimination.

Key words: bismuth intoxication, acute kidney injury, dimercaprol, teratogenicity.

Bismuth is a heavy metal with the symbol $\mathrm{Bi}$ and atomic number 83 and molecular weight $208.98 \mathrm{Da}$. Bismuth salts are insoluble and especially colloidal bismuth subcitrate (CBS) and bismuth subsalicylate, are widely used to treat peptic ulcers, functional dyspepsia, and chronic gastritis. ${ }^{1,2}$ Only small amount of bismuth (approximately \%1) is absorbed following oral administration. ${ }^{2}$ CBS has greater bioavailability than other bismuth salts; thus treatment with this form carries a higher risk of toxicity. ${ }^{2,3}$ To date, only a few reports have documented nephrotoxicity after ingestion of colloidal bismuth. We present here a case of an adolescent pregnant girl who developed acute kidney injury due to an overdose of CBS.

\section{Case Report}

A 16-year-old adolescent pregnant girl was admitted to the emergency department 30 hours after taking 20 tablets of CBS (De-Nol) in a suicide attempt. Each tablet included 300 $\mathrm{mg}$ of CBS, which is equivalent to $120 \mathrm{mg}$ of bismuth oxide $\left(\mathrm{Bi}_{2} \mathrm{O}_{3}\right)$. She had symptoms of nausea and vomiting and looked anxious on admission. Intermittent vomiting was present for 24 hours prior to admission to hospital. Physical examination upon admission was unremarkable: blood pressure 110/70 mm $\mathrm{Hg}$, pulse 82 beats/minute, respiration rate 16 breaths/minute, and body temperature $36.5^{\circ} \mathrm{C}$. Laboratory tests were as follows: white blood cell count $18,300 / \mathrm{mm}^{3}$, hemoglobin, $15.4 \mathrm{~g} /$ $\mathrm{dl}$, platelet count $290,000 / \mathrm{mm}^{3}$, blood urea nitrogen (BUN) $24 \mathrm{mg} / \mathrm{dl}$, serum creatinine $1.92 \mathrm{mg} / \mathrm{dl}$, sodium $136 \mathrm{mEq} / \mathrm{L}$, potassium 3.69 $\mathrm{mEq} / \mathrm{L}$, chloride $111 \mathrm{mEq} / \mathrm{L}$, calcium $8.5 \mathrm{mg} / \mathrm{dl}$, phosphorus $3.1 \mathrm{mg} / \mathrm{dl}$, magnesium $2.5 \mathrm{mg} / \mathrm{dl}$, glucose $98 \mathrm{mg} / \mathrm{dl}$, aspartate aminotransferase (AST) $17 \mathrm{U} / \mathrm{L}$, alanine aminotransferase (ALT) 
$7 \mathrm{U} / \mathrm{L}$, lactate dehydrogenase (LDH) 276 $\mathrm{U} / \mathrm{L}$, albumin $4.1 \mathrm{~g} / \mathrm{dl}$. Arterial blood gases showed metabolic acidosis $\left(\mathrm{pH}\right.$ 7.31, $\mathrm{PaCO}_{2}$ 22,4 mmHg, $\mathrm{PaO}_{2} 52.7 \mathrm{mmHg}$, base excess $-17 \mathrm{mmol} / \mathrm{L}$, and $\mathrm{HCO} 314.6 \mathrm{mmol} / \mathrm{L})$. The blood bismuth level on admission was 102.1 $\mu \mathrm{g} / \mathrm{L}$ (normal <0.8). The quantification of $\mathrm{Bi}$ in the blood was determined by atomic absorption spectrophotometry (AAS/ICP-MS). Beta human chorionic gonadotropin level in the blood was high $(150.07 \mathrm{mIU} / \mathrm{ml}$; normal<5). Abdominal ultrasonography (US) demonstrated severely increased echogenicity on both renal parenchyma. Transvaginal US detected an early pregnancy at 5 weeks, 4 days. Urine dipstick testing and microscopy revealed proteinuria $(+3)$, hematuria with red blood cells of normal morphology and pyuria. Decontamination of Bi was performed by gastric lavage and appropriate fluid therapy. The patient rapidly became oliguric $(500 \mathrm{ml} /$ day) and blood creatinine level increased to $4.34 \mathrm{mg} / \mathrm{dl}$ (BUN $31 \mathrm{mg} /$ dl) during the first 48 hours of admission. Fractional $\mathrm{Na}$ excretion, renal failure index or tubular phosphate excretion could not be measured in the patient due to oliguria. After consultation with Turkish National Drug and Poison Information Center, a chelation therapy with parenteral dimercaprol, also known as British anti-Lewisite (BAL; 2,3-dimercapto-1propanol) was started and continued for 14 days. Continuous venovenous hemodiafiltration (CVVHD) with high-flux membrane was carried out in the first 3 days of chelating therapy in the intensive care unit. We stopped CVVHD after 72 hours and then intermittent hemodialysis (HD) was prescribed daily (4 hours/day) for the first 4 days and then three times (4 hours/day) weekly for one week. The patient's urine output progressively increased and renal function tests comprising arterial blood gas analysis gradually improved. We could not measure $\mathrm{Bi}$ level in any body fluid or dialysate fluid except in the blood sample received before initiation of extracorporeal renal replacement therapy (RRT) as the patient's insurance did not pay for the testing. The patient recovered clinically and was discharged at 21 days of hospitalization. Her gradual improvement in renal functions continued after discharge. Her serum creatinine and BUN levels 45 days after discharge were $0.69 \mathrm{mg} / \mathrm{dl}$ and $12.2 \mathrm{mg} / \mathrm{dl}$, respectively. At this time the urinalysis results were also normal. The council of perinatalogy and obstetrics counselled the pregnancy at 9 weeks and recommended termination of the pregnancy due to potential teratogenic effects of high dose bismuth exposure and parental dimercaprol treatment; but the the patient and her partner preferred continuation of the pregnancy. The pregnancy proceeded well within normal limits. The patient gave birth to a term healthy baby boy with vaginal delivery. We could not measure the Bi level either in blood or urine sample as the baby's insurance did not pay for the testing. At the last visit, the baby was 6 months old with normal growth and development as well as normal kidney functions. Neither deterioration in renal functions nor emergence of proteinuria was recorded in the patient during follow-up care after hospital discharge. Informed consent was obtained from the participant and the family included in the study.

\section{Discussion}

The absorption of bismuth salts depends on the bismuth compound applied, dissolution of tablets, gastric and duodenal $\mathrm{pH}$, and gastric emptying. ${ }^{3,4}$ In blood, bismuth is thought to be primarily present in red blood cells possibly binding to glutathione inside the cells, and the remaining portion is transported bound to transferrin, albumin, alpha-2-microglobulin, immunoglobulin $\mathrm{M}$, beta-lipoprotein, and haptoglobin and distributes widely throughout tissues. ${ }^{5,6}$ Bismuth accumulates in kidney, liver, spleen, bone (metaphysis), lung, heart, and muscle. Bismuth forms strong covalent bonds with sulfhydryl groups of cellular proteins including vital enzymes ${ }^{4}$. The halflife of bismuth in blood varies from 3.5 minutes to $17-22$ years. This extreme variation is because of bismuth's accumulation and resecretion from tissues. ${ }^{3}$ The most common side effects of high dose bismuth intake are encephalopathy, nephropathy, osteoarthropathy, gingivostomatitis, and colitis.4,7-11 The possible toxicity occurs at serum bismuth concentrations above $50 \mu \mathrm{g} / \mathrm{L} .{ }^{10}$ CBS is a complex bismuth salt of citric acid which is soluble in water but precipitates at $\mathrm{pH}$ less than $5 .^{3}$ After receiving CBS, the bioavailability of bismuth ranges from 0.16 to $0.28 \%$. and the blood clearance of bismuth ranges from 50 to $95 \mathrm{ml} / \mathrm{min}^{6}{ }^{6}$ The bismuth concentration typically increased to a 
maximum within the first hour after ingestion of CBS (215 mg bismuth) and decreased with half-lives of approximately $1.6 \pm 0.7 \mathrm{~h}$ in a study conducted in 20 volunteers. The authors suggested that some bismuth absorption may occur in the stomach and the upper sections of the intestine. A total of 0.03 to $1.2 \%(0.06-2.51$ $\mathrm{mg}$ ) of the ingested bismuth was eliminated via the kidneys, at the most in the first $12 \mathrm{~h}$ after ingestion in that study. ${ }^{12}$ The 91 to $93 \%$ of the ingested bismuth is eliminated via the feces within 5 days after ingestion of CBS and a few percent are stored in the human body or are eliminated via alternative pathways. ${ }^{12}$

Bismuth intoxication is a rare cause of AKI and is usually reversible if appropriately managed. Bismuth binds to a metal binding protein in proximal renal tubule cells and remains bound in this way for months. In acute nephrotoxicity, renal blood flow and glomerular filtration rate are both decreased. In experimental studies, histological examinations showed that the necrosis of the epithelial cells of the S3 segment of the proximal tubule occurs as early as 3 hours after CBS administration and is followed by a similar event in the S1/S2 segment 3-12 hours later. ${ }^{8}$ Acute tubular necrosis has been the most encountered pathology in several case reports which also occurred in our patient.4,7-11 Both reversible and irreversible Fanconi's syndrome were described in patients with bismuth intoxication. ${ }^{7,8}$ In such patients acute tubular damage may proceed as the release of bismuth continues from deposited tissues even if normal blood level is achieved. Accordingly, there are case reports describing patients with prolonged duration of acute renal injury in whom appropriate conventional extracorporeal methods and chelation therapy were applied and normal bismuth blood levels were achieved in a few days. ${ }^{7,11}$ Plasmapheresis is effective in elimination of substances which remain highly bound to plasma proteins and low distribution volume. ${ }^{13}$ Disel et al. ${ }^{14}$ described a patient with bismuth intoxication who was treated with plasmapheresis along with HD and achieved a quick recovery of AKI. The authors suggested that the quick recovery might be relevant to plasmapheresis that cleared circulating bismuth compounds. As bismuth tightly binds to plasma proteins, plasmapheresis may be an alternative method for extracorporeal elimination in patients with bismuth intoxication and AKI.
We did not perform plasmapheresis in our patient because of limited experience of its usage in heavy metal intoxication and of also non-availability of the machine in our hospital.

Continuous renal replacement therapy (CRRT) is a blood purification technique used to treat the most severe forms of AKI. In CVVHD, diffusive transport of molecules is combined with convective removal in order to mainly improve the clearance of small solutes. CRRT as a preferable modality in hemodynamically unstable patients with AKI. The membranes used in CRRT are typically more permeable compared to standard intermittent HD membranes. CRRT membranes allow for the clearance of molecules as large as 20,000$40,000 \mathrm{Da}$. Another advantage of CRRT is the ability to avoid rebound of toxins removed from intravascular space, due to continuous nature of the procedure and slower rate of clearance, leading to less dramatic decreases in plasma drug levels and slower reequilibration of toxins between intracellular and intravascular spaces ${ }^{15}$. The molecular weight of bismuth is $208.98 \mathrm{Da}$ and conventional intermittent HD or peritoneal dialysis combined with chelating agent seems to be an appropriate therapeutic measure for the treatment of AKI developed due to bismuth intoxication. Hence, many of reported cases with bismuth intoxication and AKI benefited from these treatment modalities 8,11,16. Elmas et al. ${ }^{17}$ also reported recovery of renal functions in a 16 year-old girl who developed AKI after ingestion of CBS. She had received $10.5 \mathrm{~g} \mathrm{CBS}$ (35 tablets De-Nol), 7 days before admission. She was treated with HD, CVVHD (for 72 hours) and penicillamine as a chelator agent. The authors suggested that CVVHD could be an alternative therapy for AKI due to CBS intoxication. We performed CVVHD in the first 72 hours of hospital stay in our patient because she had to be hemodinamically stable due to pregnancy and of concern of rebound of toxicity. High-flux, non-celluloses membrane used for HD has increased permeability and is capable of removing moderate-sized molecules between 10000 to 15000 Dalton, including many of the inflammatory proteins, $\beta_{2}$ microglobulin and lipoproteins. Some authors suggest the use of high-flux membranes will improve the adequacy of dialysis. ${ }^{18}$ We stopped CVVHD after 72 hours and then intermittent HD was prescribed. The dialysis frequency in our 
patient was determined according to treatment schedules described in case reports with bismuth intoxication in whom chelation therapy and HD were performed for the treatment of AKI. $7,8,11,14,17$

Although the placenta is permeable to bismuth, no teratogenicity has been reported in humans. On the other hand, bismuth is considered as possibly unsafe during lactation ${ }^{19}$. Neither major nor minor congenital malformation was observed in the baby described here. Normal developmental milestones were reached by the baby according to his age during every visit. The patient did not stop breastfeeding her baby, either.

There are few case reports describing the effectiveness of chelating agents including dimercaprol, sodium 2,3-dimercapto-1propanesulfonate (DMPS) or dimercaptosuccinic acid (DMSA; succimer) when combined with HD in the management of poisoning by bismuth $^{7,8,20}$. Succimer is administered orally because of its water-soluble pattern. It is well-tolerated, it has relatively low toxicity ${ }^{20}$. It would be unsafe to treat our patient with oral medication as she was very anxious and irritable in the first day of administration. Also, we could not achieve any drug other than dimercaprol in the limited adverb of time, either.

Dimercaprol (British anti-Lewisite (BAL) in Oil) is used to treat acute poisoning by arsenic, mercury, gold, and lead. There are also case reports reporting the effectiveness of dimercaprol in antimony, thallium, or bismuth poisoning. The sulfhydryl groups of dimercaprol form complexes with certain heavy metals thus preventing or reversing the metallic binding of sulfhydryl-containing enzymes. The complex is excreted. The sustained presence of dimercaprol promotes continued excretion of the metallic poisons. Common side effects include high blood pressure accompanied by tachycardia, pain at the site of injection, vomiting, and fever. $^{21}$

Its pregnancy category is C. Dimercaprol is teratogenic in mice and has been associated with increased mortality, growth restriction, cleft facial features, cerebral herniation and abnormal digit. ${ }^{22}$ It is not known whether BAL in Oil can cause fetal harm when administered to a pregnant woman, or can affect reproduction capacity. ${ }^{23}$ It should be given only if the potential benefit justifies the potential risk to the fetus. Despite the described potential side effects regarding bismuth intake in a toxic dose and also to parenteral dimarcaprol treatment, we did not observe any of these in our patient.

The American Association of Poison Control Centers and the European Association of Poisons Centres and Clinical Toxicologists have issued a joint statement that gastric lavage should not be employed routinely, if ever, in the management of poisoned patients ${ }^{24}$. However, in the case of recent and potentially lethal ingestion, the procedure may be considered after carefully weighing the well-documented risks against the unclear benefits. Nevertheless the time interval when to perform gastric lavage in intoxication may be extended to 24 hours after intoxication according to some authors' opinion. ${ }^{25}$ It is a challenge why we performed gastric lavage 30 hours after CBS ingestion despite its low yield, the doubt about the accuracy of an pregnant adolescent's report of drug use led us to perform this procedure.

We have described the first case of an adolescent pregnant patient with AKI after ingestion of CBS in a suicide attempt. In cases of AKI due to an overdose of CBS, treatment with dimercaprol combined with high flux hemodiafiltration and subsequently HD appears to be both useful and safe for bismuth elimination. Clinicians should be aware that AKI can occur after bismuth intoxication.

\section{REFERENCES}

1. Keogan DM, Griffith DM. Current and potential applications of bismuth-based drugs. Molecules 2014; 19: 15258-15297.

2. Lambert JR, Midolo P. The actions of bismuth in the treatment of Helicobacter pylori infection. Aliment Pharmacol Ther 1997; 11 (Suppl 1): 27-33.

3. Wagstaff AJ, Benfield P, Monk JP. Colloidal bismuth subcitrate. A review of its pharmacodynamic and pharmacokinetic properties, and its therapeutic use in peptic ulcer disease. Drugs 1988; 36: 132-157.

4. Bradley B, Singleton M, Li Wan Po A. Bismuth toxicity-a reassesment. J Clin Pharm Therapeut 1989; 14: 423-441.

5. Sun H, Li H, Mason AB, Woodworth RC, Sadler PJ. Competitive binding of bismuth to transferrin and albumin in aqueous solution and in blood plasma. $\mathrm{J}$ Biol Chem 2001; 276: 8829-8835.

6. Sun H, Szeto KY. Binding of bismuth to serum proteins: implication for targets of $\mathrm{Bi}(\mathrm{III})$ in blood plasma. J Inorg Biochem 2003; 94: 114-120. 
7. Erden A, Karahan S, Bulut K, et al. A case of bismuth intoxication with irreversible renal damage. Int $\mathrm{J}$ Nephrol Renovasc Dis 2013; 6: 241-243.

8. Cengiz N, Uslu Y, Gök F, Anarat A. Acute renal failure after overdose of colloidal bismuth subcitrate. Pediatr Nephrol 2005; 20: 1355-1358.

9. Serfontein WJ, Mekel R. Bismuth toxicity in man II. Review of bismuth blood and urine levels in patients after administration of therapeutic bismuth formulations in relation to the problem of bismuth toxicity in man. Res Commun Chem Pathol Pharmacol 1979; 26: 391-411.

10. Leussink BT, Slikkerveer A, Krauwinkel WJ, et al. Bismuth biokinetics and kidney histopathology after bismuth overdose in rats. Arch Toxicol 2000; 74: 349-355.

11. Hruz P, Mayr M, Low R, Drewe J, Huber G. Fanconi's syndrome, acute renal failure, and tonsil ulcerations after colloidal bismuth subcitrate intoxication. Am J Kidney Dis 2002; 39: E18.

12. Boertz J, Hartmann LM, Sulkowski M, et al. Determination of trimethylbismuth in the human body after ingestion of colloidal bismuth subcitrate. Drug Metab Dispos 2009; 37: 352-358.

13. Nenov VD, Marinov P, Sabeva J, Nenov DS. Current applications of plasmapheresis in clinical toxicology. Nephrol Dial Transplant 2003; 18 (Suppl 5): v56-v58.

14. Disel NR, Açikalin A, Sebe A, Gokel Y. Utilization of plasmapheresis in the management of bismuth intoxication with acute renal failure. Saudi J Kidney Dis Transpl 2017; 28: 629-632.

15. Mirrakhimov AE, Barbaryan A, Gray A, Ayach T. The role of renal replacement therapy in the management of pharmacologic poisonings. Int J Nephrol 2016; 2016: 3047329.

16. Işlek I, Uysal S, Gök F, Dündaröz R, Küçüködük S. Reversible nephrotoxicity after overdose of colloidal bismuth subcitrate. Pediatr Nephrol 2001; 16: 510-514.
17. Elmas AT, Tabel Y. Acute kidney injury associated with rapid treatment of hemodiafiltration for bismuth intoxication: Update and review of the literature. J Turgut Ozal Med Cent 2013; 20: 344-347.

18. Oshvandi K, Kavyannejad R, Borzuo SR, Gholyaf M. High-flux and low-flux membranes: efficacy in hemodialysis. Nurs Midwifery Stud 2014; 3: e21764.

19. Mahadevan U, Kane S. American gastroenterological association institute technical review on the use of gastrointestinal medications in pregnancy. Gastroenterology 2006; 131: 283-311.

20. Slikkerveer A, Noach LA, Tytgat GN, Van der Voet GB, De Wolff FA. Comparison of enhanced elimination of bismuth in humans after treatment with meso-2,3dimercaptosuccinic acid and D,L-2,3-dimercaptopropane1-sulfonic acid. Analyst 1998; 123: 91-92.

21. Vilensky JA, Redman K. British anti-Lewisite (dimercaprol): an amazing history. Ann Emerg Med 2003; 41: 378-383.

22. Gomez M, Sanchez DJ, Colomina MT, Domingo JL, Corbella J. Evaluation of the protective activity of BAL (2,3-dimercaptopropanol) and DMPS (sodium 2,3-dimercaptopropane-1-sulfonate) on methylmercuryinduced developmental toxicity in mice. Arch Environ Contam Toxicol 1994; 26; 64-68.

23. Domingo JL. Developmental toxicity of metal chelating agents. Reprod Toxicol 1998; 12: 499-510.

24. Vale JA, Kulig K; American Academy of Clinical Toxicology;European Association of Poison Centres and Clinical Toxicologists. Position paper: gastric lavage. J Toxicol Clin Toxicol 2004; 42: 933-943.

25. Večera R, Ondra P, Jezdinský J, Adamus M. Gastric lavage after peroral intoxication--controversial views. Cas Lek Cesk 2015; 154: 174-175. 